\title{
Load Frequency Control in a Multi-Area Deregulated Power System with BBBC-based Discrete Fractional Order Control Scheme
}

\author{
NAGENDRA KUMAR, \\ Electrical and Electronics Department, G.L.B. I. T.M. Greater Noida Uttar Pradesh, 201306, INDIA \\ ORCHID ID: 0000-0003-3464-6566 \\ BARJEEV TYAGI \\ Electrical Department, I. I. T. Roorkee, Uttrakhand, 247667, INDIA \\ VISHAL KUMAR \\ Electrical Department, I. I. T. Roorkee, Uttrakhand, 247667, INDIA
}

\begin{abstract}
Load frequency control (LFC) for multi-area restructured power system using discrete control scheme has been suggested in this paper. The proposed LFC scheme utilizes synchronously measured data of frequency and tie-line power to calculate area control error (ACE). A discrete non-integer proportional integral derivative controller (D-FOPID) has been used to derive frequency error to zero. Two-area thermal and four-area hydro thermal deregulated power system has been used to investigate various LFC issues. The optimal factors of D-FOPID have been obtained using big bang big crunch (BBBC) algorithm. The system results under MATLAB/Simulink validate that D-FOPID effectively work under different types of contract scenarios. D-FOPID performance has also been compared to discrete proportional integral derivative controller (D-PID). Further the compliance with control standards of North American electric reliability council (NERC) has also been ensured for both the controller.
\end{abstract}

Key words: Load Frequency Control, Deregulation, Optimization, BBBC, D-FOPID, D-PID, NERC.

Received: February 13, 2020. Revised: August 31, 2020. Accepted:September 7, 2020. Published: September 9, 2020.

\section{Introduction}

From many decades, LFC has been considered one of the most significant services in power system which serves two purposes i.e., maintain system frequency and tie-line flow deviations in the prescribed limits [1]. After deregulation, electricity sector restructured and divided into Gencos, Transcos, Discos, and ISO (Independent system operator) to equalize the generation and load demands. Various issues/modification/changes related to LFC after the restructuring of power system has been given in [2], however the basic role of LFC is still continue even in modern power system too. Power system is an interconnection of control areas, which are generally located at a remote place, from dispatch centers. Therefore, the information regarding the system data i.e. tie-line power/frequency has to be transferred through the data links from remote location to the dispatch center. This data transfer introduces a propagation delay which has the adverse effect on the system [34]. This time delay in a supervisory control and data acquisition (SCADA) based LFC scheme is as high as 2-10 seconds [5]. Therefore, nowadays wide area monitoring (WAM) technology which uses a digital recording device known as phasor measurement unit (PMU) is in practice. PMU deals with discrete samples of information pertaining to the system 
(voltage, current, frequency and power) at a particular time stamp. The challenges, advantages and the applications of WAM technology are highlighted in [6-7]. The deployment of the PMU in the present day power system has made the measurements very fast. Normally the PMU rate is 30-60 samples/second. This higher sampling rate can reveal new information regarding visibility, stability and accuracy of grid. In this work, it is considered, that the PMU measurements are available for frequency and tie-line flow. Controllers play an important role in LFC scheme. LFC termed as secondary control scheme which comes into operation after the completion of the primary control (regulations) scheme's task. Controllers based on different control schemes i.e. classical, robust, adaptive, optimal, nonlinear, modern, etc. have been used and tested in the field of LFC. Further control scheme based on soft computing i.e. fuzzy (FL), ANN, ant colony (ACO), GA, PSO and many more are also applied in LFC problems. The literature given in [8-9] covers various control approaches which have been used in LFC schemes. Apart from several control schemes, Fractional order (FO) controllers are receiving increasing interest among researchers. FO controllers consist non integer derivative and integral parameters, and are using extensively in the field of designing [10], stabilization [11], automatic voltage regulator (AVR) [12] and have applications in many other areas of power system. For better working of FO controller, its parameters should also obtain optimally. Therefore, several algorithms have been used to get optimal factors of FOPID controller [13-16]. In this work, LFC scheme is analysed for two test systems i.e. 2-area thermal and 4-area hydro-thermal system. A deregulated environment with time delay of $1 \mathrm{sec}$. has been considered to investigate LFC scheme. Since, data from PMU is available in discrete form, therefore authors have designed discrete form of FOPID controller. BBBC algorithm is used to obtain parameters of the designed controller [17-18]. For different power transactions scenario, power generation (Gencos), frequency oscillations and tieline power deviations have been determined. The various results (simulation) have been obtained using MATLAB/Simulink platform. A comparative analysis is carried out between the results obtained from D-FOPID and D-PID controllers. It is seen that D-FOPID controller damp out the oscillations of various responses, with minimum settling time as compared to D-PID controller. In last, the compliance of NERC control standards has also been verified for the 4-area power system, using DFOPID and D-PID controllers.

\section{Modeling of multiarea AGC scheme}

System frequency and tie-line flow are two factors, used to keep system at stable condition. Once, a perturbation occurs, these factors get disturbed and LFC operates to bring back system at nominal operating condition. In WAM technology, measurement of frequency and tie-line flow is available in discrete nature [6-7]. To incorporate these discrete signals, the conventional LFC scheme shown in Fig. 1, [19] has been modified in this work.

In a deregulated structure a Disco can receive power from the Genco of its own/any area. This kind of power transaction is known as bilateral trading and it can be implemented using ISO only. These contracts can easily have identified using a Disco Participation Matrix (DPM), where, each element known as contract participation factor (cpf) [20-22]. Due to incorporation of transactions, tie-line power modifies in deregulated structure and can be written as given in (1), [23-24, 27, 30],

$$
\Delta \mathrm{Ptie}_{\mathrm{i}-\mathrm{new}}=\Delta \mathrm{Ptie}_{\mathrm{i}}+\sum_{\substack{\mathrm{j}=1 \\ \mathrm{j} \neq \mathrm{i}}}^{\mathrm{n}} \mathrm{Dij}-\sum_{\substack{\mathrm{j}=1 \\ j \neq i}}^{\mathrm{n}} \mathrm{Dji}
$$

where $n=$ total areas, $D_{i j}=$ Disco's demand (area-j) to the Gencos (area-i), $\mathrm{D}_{\mathrm{ji}}=$ Disco's demand (area-i) to the Gencos (area-j), $\Delta$ Ptie $_{i}=$ tie-line flow variation without bilateral contract.

A PMU measures voltage, current, frequency in terms of discrete samples at a particular time stamp. Generally, the number of samples $(\mathrm{k})$ obtained from PMU is 30-60 samples/second [24]. The time period $(\mathrm{T})$ between two samples are considered constant. After the load change the change in the frequency of area-i at any instant $\mathrm{kT}$ is given as,

$\Delta \mathrm{f}_{\mathrm{i}}(\mathrm{kT})=\mathrm{f}_{\text {nominal }}-\mathrm{f}_{\text {act_ } \mathrm{i}}(\mathrm{kT}), \mathrm{k}=0,1,2, \ldots$

where, $\mathrm{f}_{\text {nominal }}=$ nominal frequency and $\mathrm{f}_{\text {act_i }}(\mathrm{kT})=$ actual frequency of area-i. 
The scheduled tie-line flow of area-i, is given in (3),

$$
P_{\text {tie_sch_i }}=\sum_{\substack{j=1 \\ j \neq i}}^{n} P_{\text {tie_sch_i-j }}
$$

where, $\mathrm{P}_{\text {tie_sch_i-j }}(\mathrm{kT})=$ scheduled tie-line flow (area$i$ to area-j). The difference of scheduled and actual tie-line flow generates tie-line flow error, given in (4).

$$
\Delta \mathrm{P}_{\text {tie-i }}(\mathrm{kT})=\mathrm{P}_{\text {tie_sch-i }}-\mathrm{P}_{\text {tie_act-i }}(\mathrm{kT})
$$

At last, the structure of tie-line flow of area-i, can be expressed as given in (5),

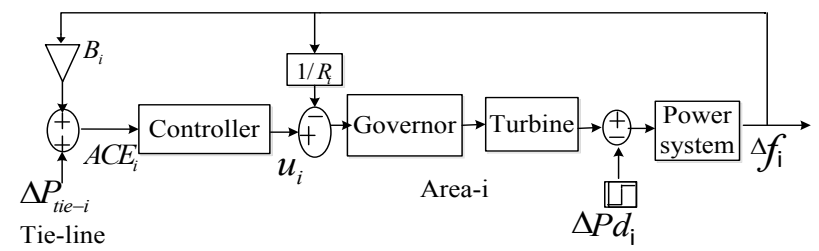

Fig. 1. Block diagram representation of $\mathrm{i}^{\text {th }}$ area LFC scheme.

$$
\Delta \mathrm{P}_{\text {tie_new }}(\mathrm{kT})=\Delta \mathrm{P}_{\text {tie-i }}(\mathrm{kT})+\sum_{\substack{\mathrm{j}=1 \\ \mathrm{j} \neq \mathrm{i}}}^{\mathrm{n}} \operatorname{Dij}(\mathrm{kT})-\sum_{\substack{\mathrm{j}=1 \\ \mathrm{j} \neq \mathrm{i}}}^{\mathrm{n}} \operatorname{Dji}(\mathrm{kT})
$$

This tie-line flow error ultimately generates ACE, which works as an input to the designed controller. For, a given instant $\mathrm{KT}$, expression of $\mathrm{ACE}$, for area-i can be represented as given in (6),

$$
\mathrm{ACE}_{\mathrm{i}}(\mathrm{kT})=\mathrm{B}_{\mathrm{i}} \Delta \mathrm{f}_{\mathrm{i}}(\mathrm{kT})+\Delta \mathrm{Ptie}_{\mathrm{i} \text {-new }}(\mathrm{kT})
$$

Fig. 2 shows the modified LFC scheme of $i^{\text {th }}$ area power system, under restructured environment considering bilateral and Poolco transactions.

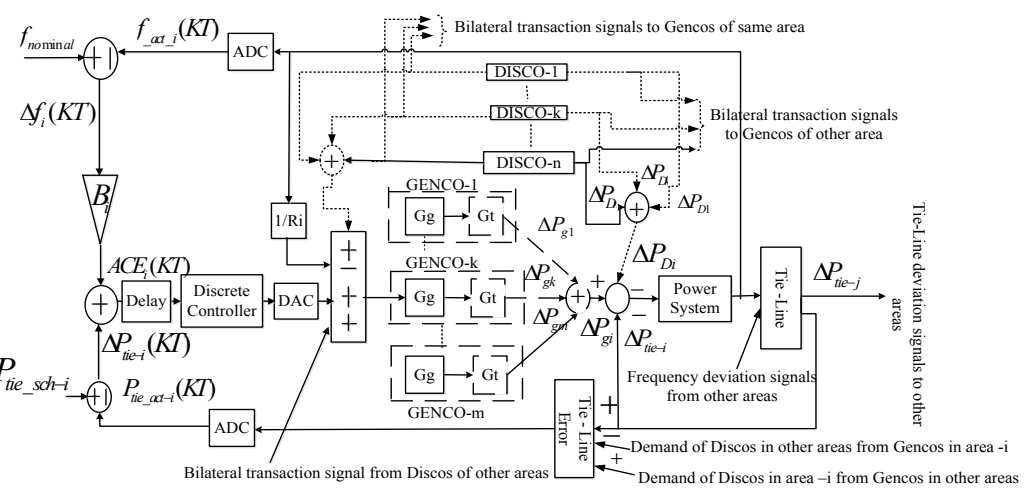

Fig. 2. LFC scheme of ith area deregulated environment.

\section{Control Design Scheme}

A decent control scheme is necessary to bring system at balance, if subjected to a sudden load perturbation. To do so, authors have designed currently used FO based control scheme. Since it is assumed that data is available in discrete form, therefore, discrete version of FOPID control scheme i.e., D-FOPID have been designed. One more control scheme i.e. discrete PID (D-PID) has also been used as secondary controller to bring back the system at balance.

The structure of a D-PID controller is given in (7).

$$
\mathrm{G}_{\mathrm{PID}}(\mathrm{z})=\mathrm{K}_{\mathrm{P}}+\frac{\mathrm{K}_{\mathrm{I}} \mathrm{T}_{\mathrm{s}} \mathrm{z}}{\mathrm{z}-1}+\frac{\mathrm{K}_{\mathrm{D}} \mathrm{N}(\mathrm{z}-1)}{\left(1+\mathrm{NT}_{\mathrm{s}}\right) \mathrm{z}-1}
$$

Apart from many advantages, PID has limitations like time to time tuning, lagging in response, nonoptimal performance in nonlinear system. Therefore, researcher have shifted their focus to non-integer PID control scheme i.e. FO control scheme. The well-known fractional integral derivative is given by

Riemann-Liouville [24-25]. Further, implementation of FO transfer function is proposed by Oustaloup, which is reported in [25]. FOPID controller can be represented as given in (8) [24-27].

$\mathrm{u}(\mathrm{t})=\mathrm{K}_{\mathrm{Pf}} \mathrm{e}(\mathrm{t})+\mathrm{K}_{\mathrm{If}} \mathrm{D}^{-\lambda} \mathrm{e}(\mathrm{t})+\mathrm{K}_{\mathrm{Df}} \mathrm{D}^{\mu} \mathrm{e}(\mathrm{t})$

where, $\mathrm{D}=\frac{\mathrm{d}}{\mathrm{dt}}$. FOPID controller can also be represented as (9).

$$
\mathrm{G}_{\mathrm{FOPID}}(\mathrm{s})=\left[\mathrm{K}_{\mathrm{Pf}}+\frac{\mathrm{K}_{\mathrm{If}}}{\mathrm{s}^{\lambda}}+\mathrm{K}_{\mathrm{Df}} \mathrm{s}^{\mu}\right]
$$

where $\mathrm{K}_{\mathrm{Pf}}, \mathrm{K}_{\mathrm{If}}, \mathrm{K}_{\mathrm{Df}}=$ FOPID gains, $\lambda$ and $\mu=$ fractional integrator and differentiator. D-FOPID can be obtained after the discretization of FOPID controller given in (9), after placing $\mathrm{s}=\mathrm{w}\left(\mathrm{z}^{-1}\right)$ which is known as generating function. In direct discretizing approach, generating function can be written as given in (10) [28-29].

$$
\left(\mathrm{w}\left(\mathrm{z}^{-1}\right)\right)^{ \pm \mathrm{r}} \approx\left(\frac{1+\mathrm{a}}{\mathrm{T}_{\mathrm{s}}}\right)^{ \pm \mathrm{r}}\left(\frac{1-\mathrm{z}^{-1}}{1+\mathrm{az}^{-1}}\right)^{ \pm \mathrm{r}}
$$


where $\mathrm{T}_{\mathrm{s}}=$ sampling period, $\mathrm{r}=\lambda$ for integral, and $\mathrm{r}=\mu$ for derivative part, $a=$ approximation (Tustin/ Euler) coefficient.

In this paper, Al-Alaoui operator (Tustin + Euler) based discretization given in (11), is used to get DFOPID control scheme [29]

$\left(\mathrm{w}\left(\mathrm{z}^{-1}\right)\right)^{ \pm \mathrm{r}} \approx\left(\frac{8}{7 \mathrm{~T}_{\mathrm{s}}} \frac{1-\mathrm{z}^{-1}}{1+\mathrm{z}^{-1} / 7}\right)^{ \pm \mathrm{r}}$

After approximating (11) using CFE, the discretization function can be written as given in (12),

$\left(\mathrm{w}\left(\mathrm{z}^{-1)}\right)\right)^{ \pm \mathrm{r}} \approx\left(\frac{8}{7 \mathrm{~T}_{\mathrm{s}}}\right)^{ \pm \mathrm{r}} \mathrm{CFE}\left\{\left(\frac{1-\mathrm{z}^{-1}}{1+\mathrm{z}^{-1} / 7}\right)^{ \pm \mathrm{r}}\right\}_{\mathrm{p}, \mathrm{q}}=\left(\frac{8}{7 \mathrm{~T}_{\mathrm{s}}}\right)^{ \pm \mathrm{r}} \frac{\mathrm{P}_{\mathrm{p}}\left(\mathrm{z}^{-1}\right)}{\mathrm{Q}_{\mathrm{q}}\left(\mathrm{z}^{-1}\right)}$

where $\mathrm{p}$ and $\mathrm{q}=$ approximation's order, $\mathrm{P}$ and $\mathrm{Q}=$ polynomials (degree $\mathrm{p} / \mathrm{q}$ ).

Finally, the expression of D-FOPID controller can be written as given in

$\mathrm{G}_{\mathrm{D}-\mathrm{FOPID}}(\mathrm{z})=\left[\mathrm{K}_{\mathrm{Pf}}+\frac{\mathrm{K}_{\mathrm{If}}}{\left(\mathrm{w}\left(\mathrm{z}^{-1}\right)\right)^{\lambda}}+\mathrm{K}_{\mathrm{Df}}\left(\mathrm{w}\left(\mathrm{z}^{-1}\right)\right)^{\mu}\right]$

On putting the value of $w\left(z^{-1}\right)$ from (12) to (13), the D-FOPID structure can be written as given in (14)

$\mathrm{G}_{\text {D-FOPID }}\left(\mathrm{z}^{-1}\right)=\mathrm{K}_{\mathrm{pf}}+\mathrm{K}_{\mathrm{If}}\left(\frac{8}{7 \mathrm{~T}_{\mathrm{s}}}\right)^{\lambda} \mathrm{CFE}_{\lambda}+\mathrm{K}_{\mathrm{Df}}\left(\frac{8}{7 \mathrm{~T}_{\mathrm{s}}}\right)^{\mu} \mathrm{CFE}_{\mu}$

The optimization problem to obtain effective parameters of D-FOPID and D-PID controllers has been determined by minimization of mean square of ACE as given in (15).

$\mathrm{J}=\frac{1}{\mathrm{n}} \sum_{\mathrm{i}=1}^{\mathrm{n}}\left[\left(\mathrm{ACE}_{\mathrm{i}}(\mathrm{kT})\right)^{2}\right]=\frac{1}{\mathrm{n}} \sum_{\mathrm{i}=1}^{\mathrm{n}}\left[\left(\mathrm{B}_{\mathrm{i}} \Delta \mathrm{f}_{\mathrm{i}}(\mathrm{kT})+\Delta \mathrm{P}_{\text {tie- }-\mathrm{i}}(\mathrm{kT})\right]^{2}\right.$

The following constraints have also been chosen to design controllers,

$$
\begin{aligned}
& \mathrm{K}_{\mathrm{Pf}, \mathrm{i}}{ }^{\mathrm{mn}} \leq \mathrm{K}_{\mathrm{Pf}, \mathrm{i}} \leq \mathrm{K}_{\mathrm{Pf}, \mathrm{i}}{ }^{\mathrm{mx}} \\
& \mathrm{K}_{\mathrm{If}, \mathrm{i}}{ }^{\mathrm{mn}} \leq \mathrm{K}_{\mathrm{If,i}} \leq \mathrm{K}_{\mathrm{If,i}}{ }^{\mathrm{mx}} \\
& \mathrm{K}_{\mathrm{Df}, \mathrm{i}}{ }^{\mathrm{mn}} \leq \mathrm{K}_{\mathrm{Df}, \mathrm{i}} \leq \mathrm{K}_{\mathrm{Df}, \mathrm{i}} \mathrm{mx} \\
& \lambda_{\mathrm{i}}{ }^{\mathrm{mn}} \leq \lambda_{\mathrm{i}} \leq \lambda_{\mathrm{i}}{ }^{\mathrm{mx}} \\
& \mu_{\mathrm{i}}{ }^{\mathrm{mn}} \leq \mu_{\mathrm{i}} \leq \mu_{\mathrm{i}}{ }^{\mathrm{mx}}
\end{aligned}
$$

The steps determining the optimal parameters of DFOPID using BBBC are as follows [24, 27]

Step 1. The population is generated for controlle $\mathrm{X}_{\mathrm{ij}}{ }^{(\mathrm{k})}=\mathrm{X}_{\mathrm{i}(\min )}{ }^{(\mathrm{k})}+\operatorname{rand} \cdot\left(\mathrm{x}_{\mathrm{i}(\max )}{ }^{(\mathrm{k})}-\mathrm{X}_{\mathrm{i}(\min )}{ }^{(\mathrm{k})}\right)$

where $\mathrm{x}=\left[\mathrm{K}_{\mathrm{p}}, \mathrm{K}_{1}, \mathrm{~K}_{\mathrm{D}}, \lambda, \mu\right], \mathrm{k}=$ total areas, $\mathrm{i}=$ parameters, $\mathrm{j}=$ population size.
Step 2. For each population fitness function (15) is evaluated.

Step 3. center of mass given in (18) is calculated here.

$X_{c o m}=\frac{\sum_{j=1}^{p} \frac{X_{i j}{ }^{(k)}}{F_{j}}}{\sum_{j=1}^{p} \frac{1}{F_{j}}}$

Step 4. New population generated around $X_{c o m}$

$\mathrm{X}_{\mathrm{ij}(\text { (new) }}{ }^{\mathrm{k}}=\mathrm{X}_{\text {com }}+\frac{\mathrm{r} \cdot \alpha\left(\mathrm{x}_{\mathrm{i}(\max )}^{\mathrm{k}}-\mathrm{x}_{\mathrm{i}(\min )}^{\mathrm{k}}\right)}{\mathrm{K}}$

where $\alpha=$ limiting parameter, $\mathrm{r}=$ =random number, $\mathrm{K}=$ iteration

Step 5. In this step, next parameters are generated.

$\mathrm{x}_{\mathrm{ij} \text { (next) }}{ }^{\mathrm{k}}={ }_{\min }\left\{\mathrm{F}\left(\mathrm{x}_{\mathrm{ij} \text { (previous) }}^{\mathrm{k}}\right), \mathrm{F}\left(\mathrm{x}_{\mathrm{ij} \text { (new) }}{ }^{\mathrm{k}}\right)\right\}$

Step 6. It is the step where error is calculated and if it is less than the specified one, algorithm stop. This step gives optimum fitness function and respective optimal parameters of controller.

\section{Simulation Results and Discussion}

Two-area equal (thermal) and four-area unequal (hydro-thermal) power system have been simulated using MATLAB to address LFC scheme with Poolco and Bilateral transactions [23-24]. To simulate, it is assumed that the frequency/tie-line data is available from PMU. The data contains the discrete values of frequency and tie-line flow taken at sampling interval 0.0333 second [16]. The transportation delay for ACE signal has been taken as 1 second.

\subsection{Two area power system}

D-FOPID has been designed for two-area LFC scheme based on Fig. 2. In both the areas and their governor-turbine units are identical. Two Gencos (G11 and G12 in area-1 and G21 and G22 in area-2) and two Discos (D11 and D12 in area-1 and D21 and D22 in area-2) are considered in each area. The parameters of two-area LFC scheme are taken from [24]. Fig. 3 shows that BBBC provides optimal 
parameters after 10 generations while GA gives after 25 generations.

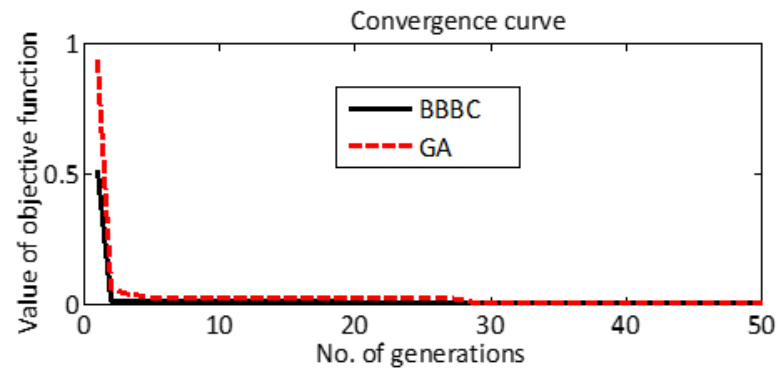

Fig. 3. Convergence curve of BBBC and GA.

Therefore, authors have used the parameters obtained using BBBC only. The parameters of BBBC and GA are given in Table 1. The optimal values of D-FOPID/D-PID parameters are given in Table 2.

\begin{tabular}{ccc}
\multicolumn{3}{c}{ Table 1: Selected parameters of BBBC/GA. } \\
\hline BBBC & 2-area & 4-area \\
Population & 30 & 40 \\
Variable to be optimized & 6 and 10 & 12 and 20 \\
Limiting parameter & 10 & 10 \\
GA & 2-area & 4-area \\
Population & 30 & 40 \\
Variable & 6 and 10 & 12 and 20 \\
Mutation & 0.01 & 0.01 \\
Crossover & 0.8 & 0.8 \\
\hline
\end{tabular}

Table 2: Optimum Values for D-FOPID and D-PID

\begin{tabular}{|c|c|c|c|c|c|c|c|c|}
\hline & \multicolumn{3}{|c|}{ DPIDC } & \multicolumn{5}{|c|}{ DFOPIDC } \\
\hline & $K_{P}$ & $K_{I}$ & $K_{D}$ & $K_{p f}$ & $K_{l f}$ & $K_{D f}$ & $\lambda$ & $\mu$ \\
\hline Area-1 & .602 & -.269 & -.005 & 0.247 & -1.056 & -.704 & -0.702 & 0.609 \\
\hline Area-2 & 1.09 & .247 & .192 & 0.473 & -0.2 & 1.654 & -0.702 & 0.609 \\
\hline
\end{tabular}

Two different cases have been simulated for 2-area LFC scheme. First case assumes a change in load in both areas, while in second case a contract violation (excess power than a contracted one) is considered.

\subsubsection{Case 1}

In this case, a step load of $0.2 \mathrm{pu}$ has been considered in area-1 $\left[0.1 \mathrm{pu} / \mathrm{Disco} 1\left(\Delta P_{L 1}\right)\right.$ and 0.1 $\left.\mathrm{pu} / \mathrm{Disco} 2\left(\Delta P_{L 2}\right)\right]$. The similar load demand of 0.2 pu has been considered in area-2 $[0.1 \mathrm{pu} / \mathrm{Disco} 3($ $\left.\Delta P_{L_{3}}\right)$ and $\left.0.1 \mathrm{pu} / \mathrm{Disco} 4\left(\Delta P_{L_{4}}\right)\right]$. The given DPM shows the various bilateral contracts between Gencos/Discos [27].

$$
D P M=\left[\begin{array}{cccc}
0.5 & 0.25 & 0 & 0.3 \\
0.2 & 0.25 & 0 & 0 \\
0 & 0.25 & 1 & 0.7 \\
0.3 & 0.25 & 0 & 0
\end{array}\right]
$$

To follow the loads perturbation, Gencos change their generation as,

$$
\left(\Delta \mathrm{P}_{\mathrm{Gi}}\right)_{\mathrm{bi}}=\sum_{\mathrm{j}} \mathrm{cpf}_{\mathrm{ij}} \Delta \mathrm{P}_{\mathrm{L}_{\mathrm{j}}} \quad \mathrm{i}=1,2,3,4
$$

where, $\Delta \mathrm{P}_{\mathrm{Lj}}=$ total load demand of $\mathrm{j}^{\text {th }}$ Disco and cpf = elements of DPM.

Therefore, for the given case, change in Gencos of area- 1 , can be determined as,

$\Delta P_{G 1}=0.5(0.1)+0.25(0.1)+0+0.3(0.1)=0.105 \mathrm{pu}$ and $\Delta P_{G 2}=0.045 \mathrm{pu}$.

The net change in Gencos of area-2 can be written as,

$$
\begin{aligned}
& \left(\Delta P_{G 3}\right)=0 \times 0.1+0.25 \times 0.1+1 \times 0.1+0.7 \times 0.1=0.195 \mathrm{pu}, \\
& \left(\Delta P_{G 4}\right)=0.3 \times 0.1+0.25 \times 0.1+0 \times 0.1+0 \times 0.1=0.055
\end{aligned}
$$

pu.

The scheduled tie-line power flow is given as,

$\Delta \mathrm{P}_{\text {tiel-2,schd }}$

$=\sum_{\mathrm{i}=1}^{2} \sum_{\mathrm{j}=3}^{4} \operatorname{cpf}_{\mathrm{ij}} \Delta \mathrm{P}_{\mathrm{L}_{\mathrm{j}}}-\sum_{\mathrm{i}=3}^{4} \sum_{\mathrm{j}=1}^{2} \mathrm{cpf}_{\mathrm{ij}} \Delta \mathrm{P}_{\mathrm{L}_{\mathrm{j}}}=-0.05 \mathrm{pu}$

The frequency of area- 1 and area- 2 on a load perturbation deviates from its nominal value as shown in Fig. 4. To bring back frequency to its scheduled value LFC initiates change in generation. It is apparent that area- 1 and area- 2 frequency differences quickly disappear and undergo less oscillations using D-FOPID controller.
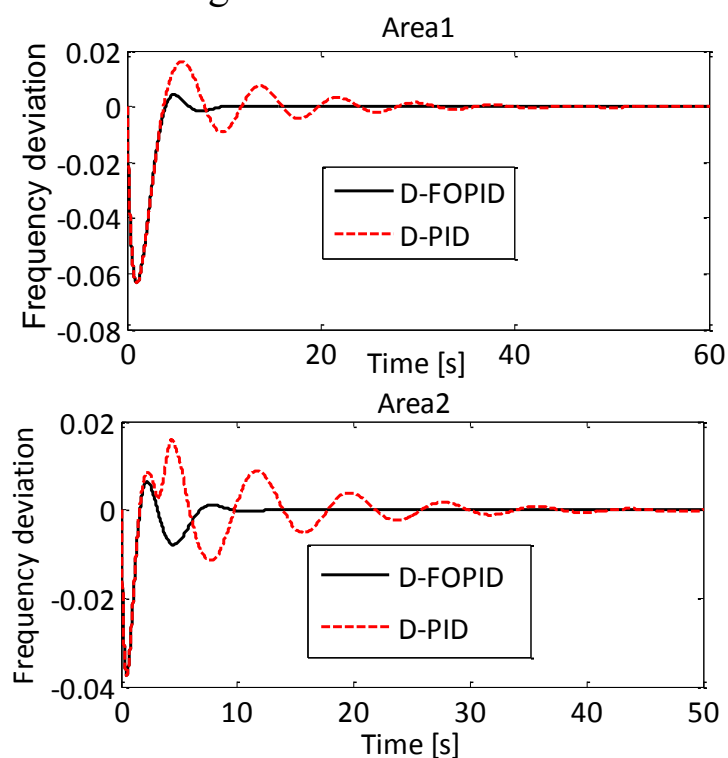

Fig. 4. Frequency deviations/area-1\&area-2 ( $\mathrm{rad} / \mathrm{s})$.

The change in the tie-line flow and change in generation is shown in Fig. 5-6 respectively. 


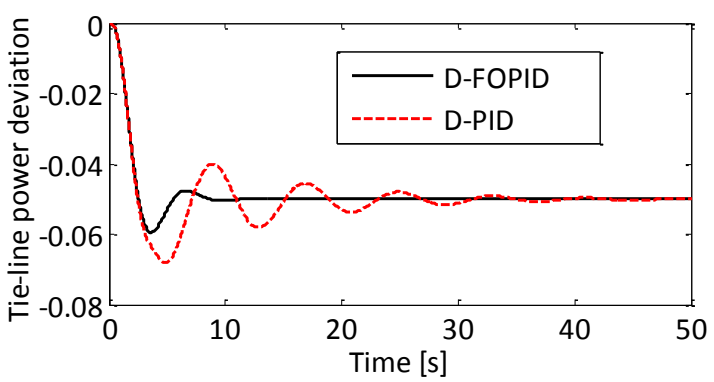

Fig. 5. Tie-line power (pu).
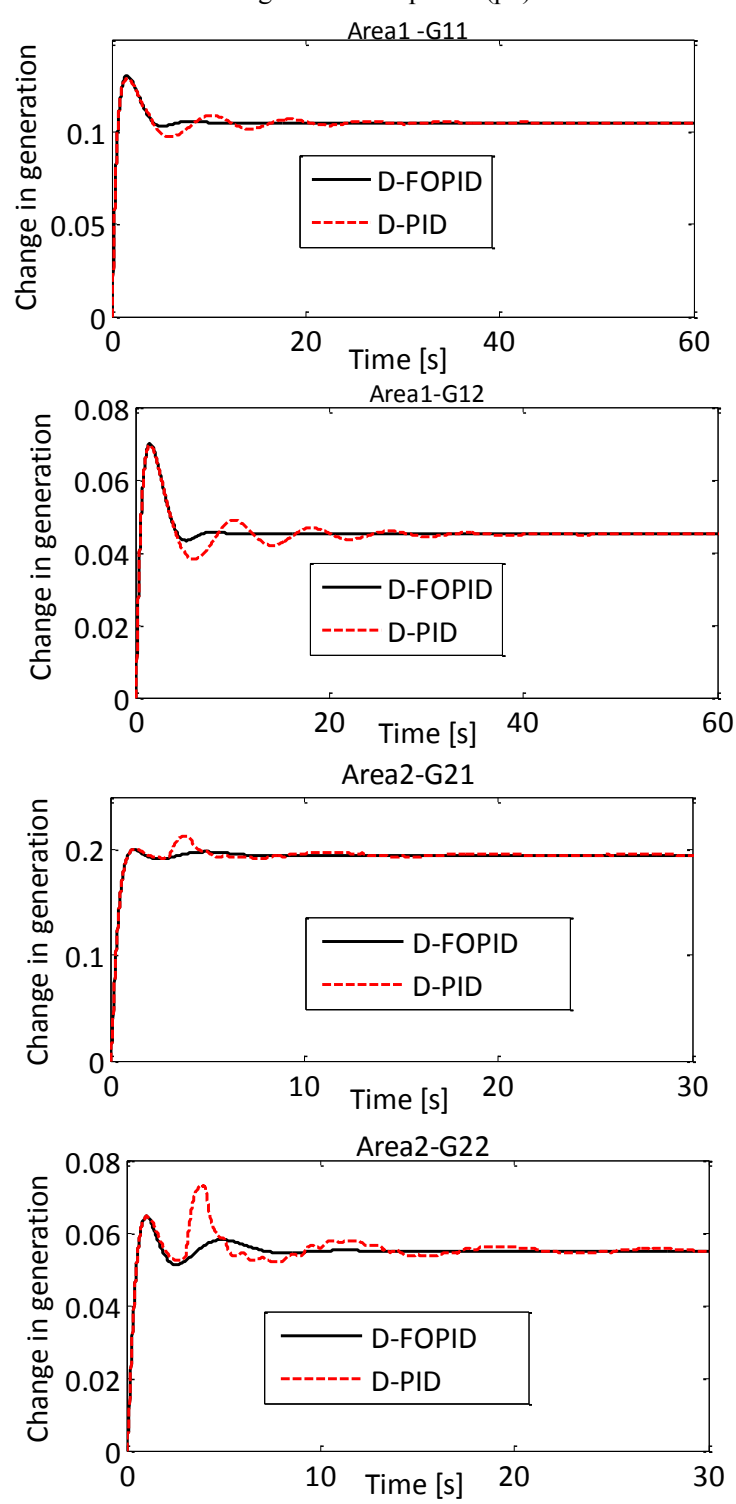

Fig. 6. Change in generated power (pu).

It is seen that Gencos of each areas and deviation in tie-line flow settled down to their desired value quickly and with fewer oscillations using D-FOPID than D-PID. The settling time for both the controllers is given in Table 3 .
Table 3: Settling time comparison of frequency deviation.

\begin{tabular}{lcccc}
\hline & \multicolumn{2}{c}{ Area-1 } & \multicolumn{2}{c}{ Area-2 } \\
\hline & D-PID & D-FOPID & D-PID & D-FOPID \\
Case1/ Settling time (sec.) & 35 & 18 & 45 & 25 \\
Case2/ Settling time (sec.) & 65 & 45 & 75 & 55 \\
\hline
\end{tabular}

\subsubsection{Case 2: Contract Violation}

In this case Disco1 of area-1, draws 0.1 pu more power (not in power contract). Therefore, to provide this extra power Gencos of area-1 will supply in excess, and it is considered that $75 \%$ of this additional demand will be provided by Gencol1 (G11) and $25 \%$ by Genco12 (G12). This case has been simulated using a load of $0.3 \mathrm{pu}$ in area- 1 and $0.2 \mathrm{pu}$ in area-2 respectively. The frequency deviations of both areas corresponding have been shown in Fig. 7. The tie-line flow exchange is given in Fig. 8. The excess load of $0.1 \mathrm{pu}$ is followed by the Gencos of area-1 only. In comparison to case1, G11 and G12 of area-1 increase their power to 0.18 pu and $0.07 \mathrm{pu}$ respectively. The Gencos of area-2 also change their powers and settled at same values as given in case1. The changes in power of Gencos are shown in Fig. 9.
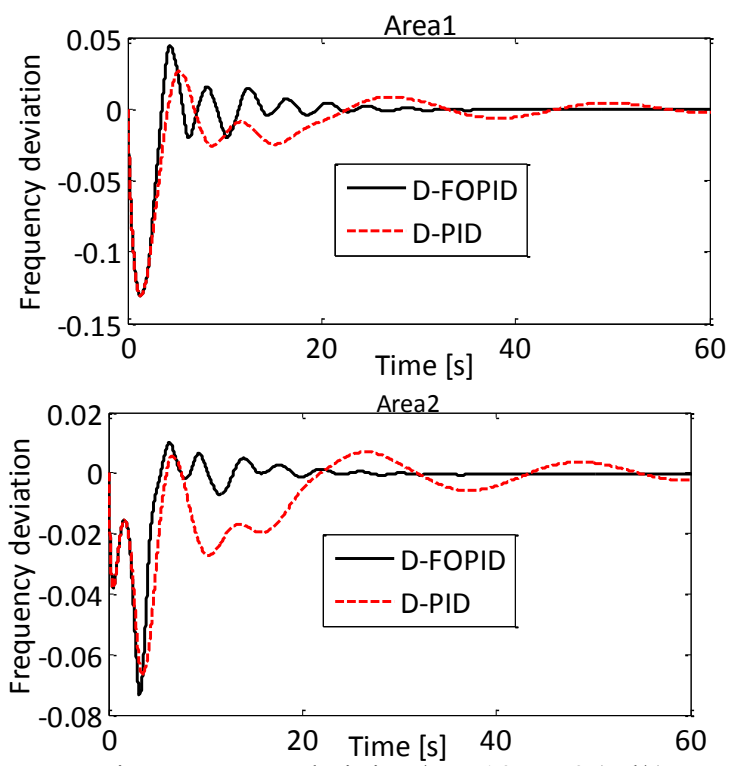

Fig. 7. Frequency deviations/area-1\&area-2 (rad/s).

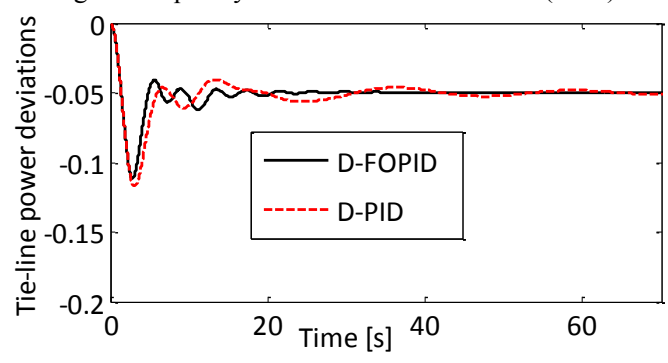

Fig. 8. Tie-line power (pu). 
WSEAS TRANSACTIONS ON POWER SYSTEMS DOI: $10.37394 / 232016.2020 .15 .19$
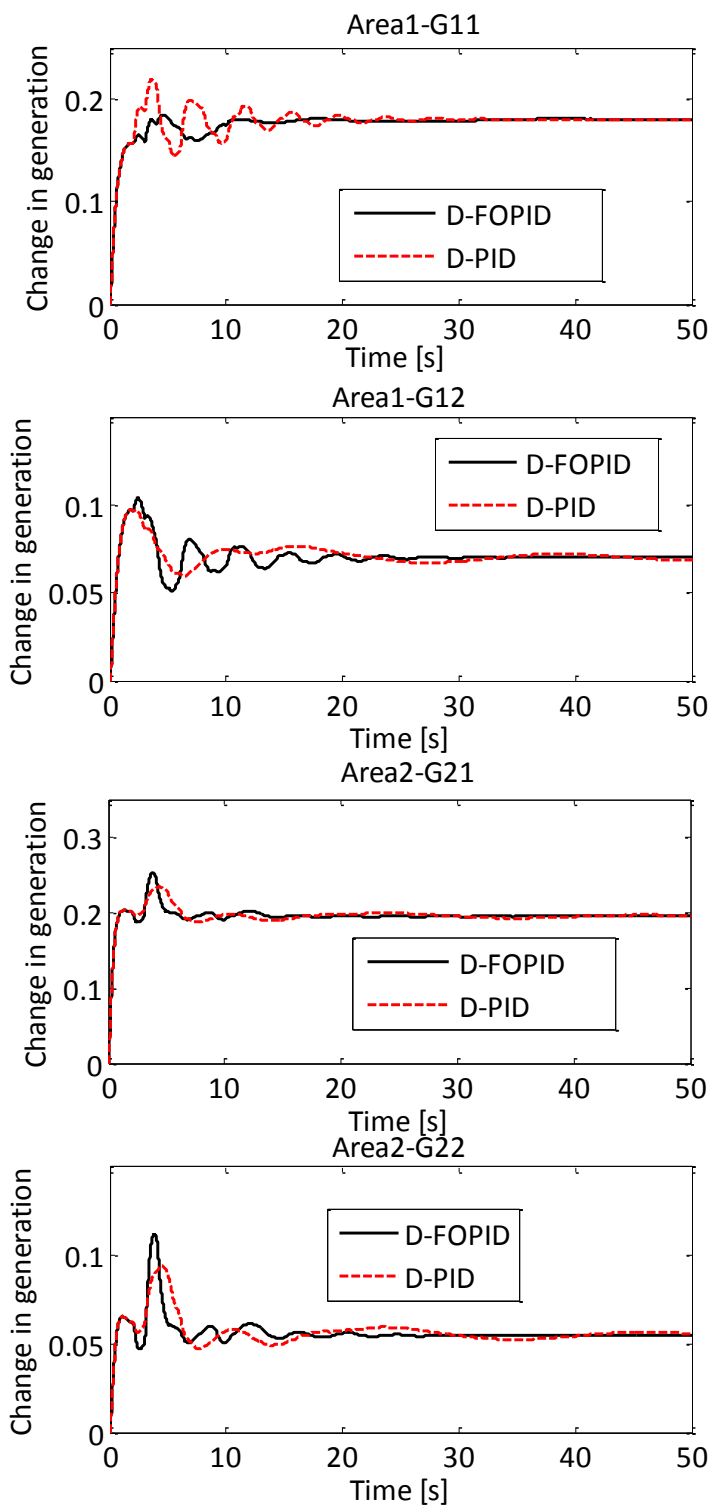

Fig. 9. Generated power (pu).

It is seen that the responses with D-FOPID controllers reach their final values in smaller settling time as compared to D-PID controllers.

\subsection{Four-Area System}

The considered, 75-bus Indian power system has been divided into 4 -areas. The rating, number of Gencos/Discos are considered same as given in [24, 27]. The Considered bids offered by Gencos and Discos to take participation in power contracts for different areas have been given in [27]. Fig. 10 shows the convergence curve of $\mathrm{BBBC}$ and GA algorithms.

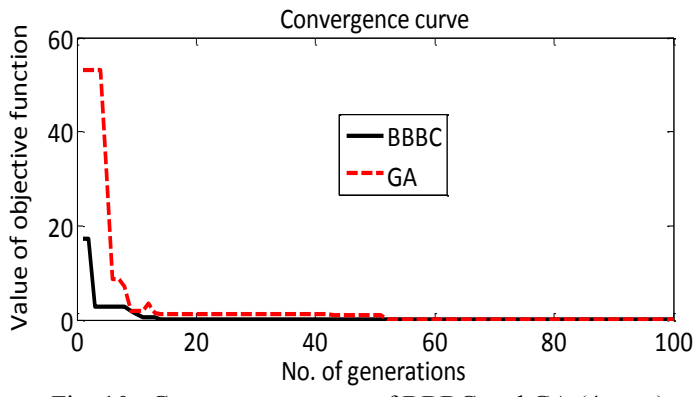

Fig. 10. Convergence curve of BBBC and GA (4-area).

Only BBBC obtained parameters have been used in this paper as given in Table 4 .

\begin{tabular}{lcccccccc}
\multicolumn{10}{c}{ Table 4: Optimum parameters of D-FOPID/D-PID. } \\
\hline \multicolumn{1}{c}{ D-PID } & \multicolumn{7}{c}{ D-FOPID } \\
\hline $\begin{array}{l}\text { Mixed } \\
\text { Transaction }\end{array}$ & $\mathrm{K}_{\mathrm{P}}$ & $\mathrm{K}_{\mathrm{I}}$ & $\mathrm{K}_{\mathrm{D}}$ & $\mathrm{K}_{\mathrm{pf}}$ & $\mathrm{K}_{\mathrm{If}}$ & $\mathrm{K}_{\mathrm{Df}}$ & $\lambda$ & $\mu$ \\
Area-1 & -0.17 & -0.211 & 0.472 & - & - & -0.399 & .1743 & .01 \\
& & & & 0.047 & 0.145 & & & \\
Area-2 & -0.334 & -0.63 & 0.982 & - & -0.26 & -0.385 & .011 & 1.028 \\
& & & & 0.134 & & -1.316 & 1.878 & .013 \\
Area-3 & -0.898 & -0.398 & 0.182 & - & - & - & \\
Area-4 & 2.223 & -0.383 & 0.289 & - & - & -0.122 & .0697 & .9681 \\
& & & & 0.893 & 0.152 & & & \\
\hline
\end{tabular}

After clearing bids, the contracted power can be executed using Poolco/bilateral or poolco + bilateral (mixed) transactions [24, 27]. In this work, following transactions have been considered and implemented.

1. G5 of area-2 is used to supply $10 \%$ of area-1 load.

2. G11 of area-4 is used to supply $20 \%$ of area- 2 load.

3. G4 of area-2 is contracted to supply $10 \%$ of area-2 load.

4. G5 of area- 2 is contracted to supply $10 \%$ load of area-4 load.

5. G12 of area- 4 is contracted to provide $20 \%$ of area-4 load.

After considering the bilateral contracts of different areas, the additional powers required in the different areas are as follows: Area- $1=45 \mathrm{MW}$, Area-2 $=35$ MW, Area-3=0 MW, Area-4=70MW. To meet out this demand, Poolco transactions have to be implemented by the ISO.

The frequency deviations corresponding to the load changes in area-1 to area-4 are shown in Fig. 11. 

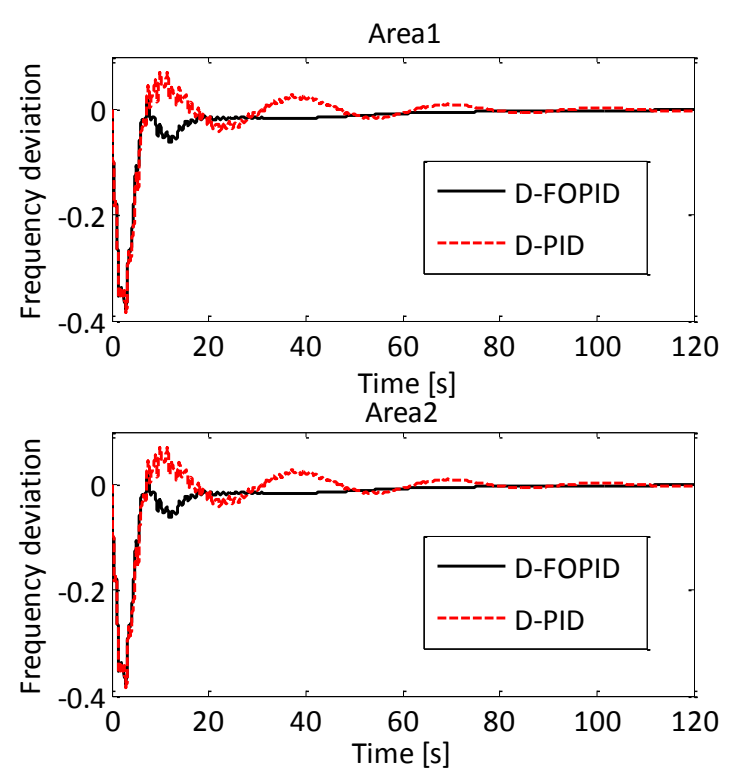

Area 3
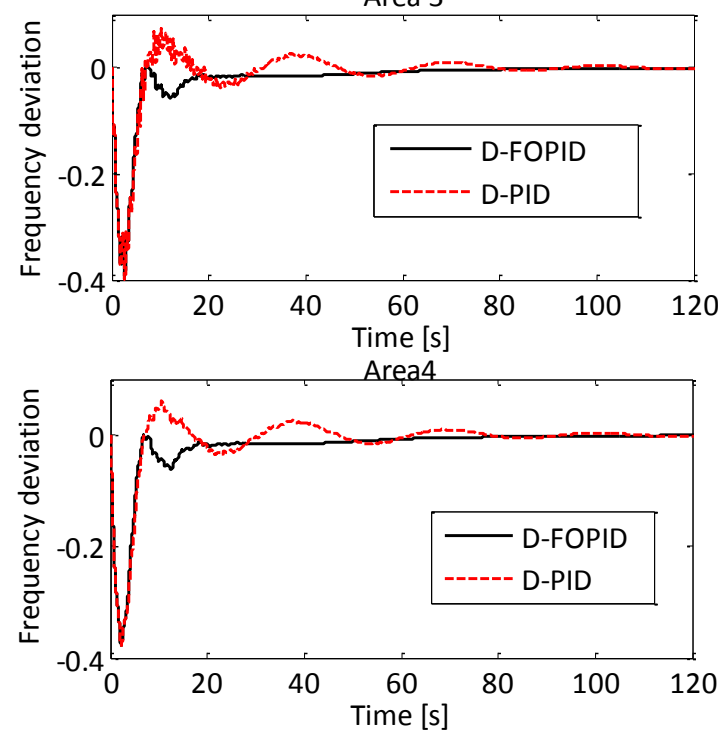

Fig. 11. Frequency deviation (Hz).

The change in Discos are similar with D-FOPID and D-PID and are given in Fig. 12.

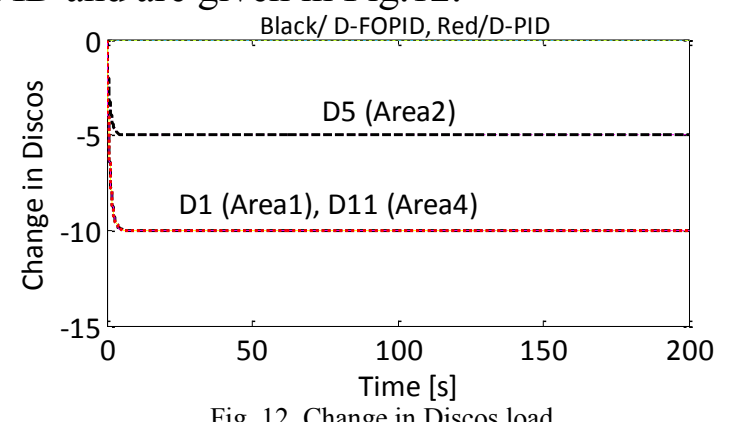

Fig. 12. Change in Discos load.

Different Gencos from area-1 to area-4 change their generation as per the given transaction and shown in Fig. 13.

Area-1: Gencos (G1 G2 and G3) do not have bilateral transactions and only participates in the
Poolco transactions. 10\% (5 MW) load of area-1 (50 MW) is supplied by the Genco5 (G5) of area-2, therefore, 45 MW power of area-1 is supplied by Gencos G1, G2, and Disco D1 as per their participation factors. G2 changes its power by 30 MW $(0.6667 * 45)$, G1 by 5 MW $(0.111 * 45)$ and D1 curtails its load by $10 \mathrm{MW}(0.2222 * 45)$.

In area-2, Genco G4 and G5 have bilateral transactions while Genco G6 and G8 are participating in the Poolco transactions. G4 changes its real power output by $5 \mathrm{MW}$ ( $10 \%$ of area- 2 load) to fulfill the bilateral contract of area-2. G5 changes its output by $15 \mathrm{MW}$ to supply $10 \%$ of area- 1 load (50MW) and $10 \%$ of area-4 load (100MW). $30 \%$ of area-2 load demand is supplied through the bilateral transactions. Therefore, G6 and G8 will share the rest of the power $(35 \mathrm{MW})$ as per their participation factors. G6 increases its real power by $5 \mathrm{~W}$ $(0.1429 * 35)$ and $\mathrm{G} 8$ by $25 \mathrm{MW}(0.7143 * 35)$. In area-3, no bilateral transaction has been considered, therefore, G9 and G10 participate in Poolco transactions as per their participation factors to fulfill the load demand (50MW) of area-3. G9 increases its real power by $15 \mathrm{MW}(0.3 * 50)$ and G10 by $35 \mathrm{MW}(0.7 * 50)$.

In area- $4,20 \%$ of area- 2 load demand (50MW) is supplied by the Genco G11. 30\% of the load demand (100MW) of area-4 is supplied through the bilateral transactions, i.e. G12 of area- 4 changes its output by $20 \mathrm{MW}$ to supply $20 \%$ of area- 4 load $(100 \mathrm{MW})$ and $10 \%$ of area-4 load is supplied by G5 of area-2. The rest of the power (70MW) will be shared by G11, G13, G15 and Disco D11 of area-4 as per their participation factors. G11 changes its power by $25 \mathrm{MW}(0.3571 * 70), \mathrm{G} 13$ by $10 \mathrm{MW}$ $(0.1429 * 70), \mathrm{G} 15$ by $25 \mathrm{MW}(0.3571 * 70)$.

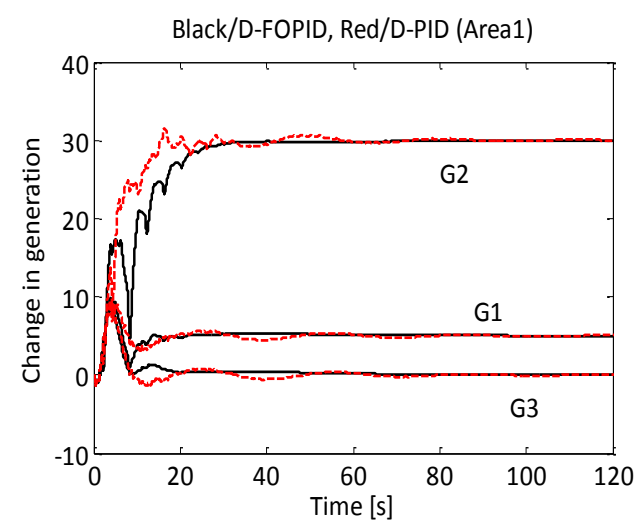



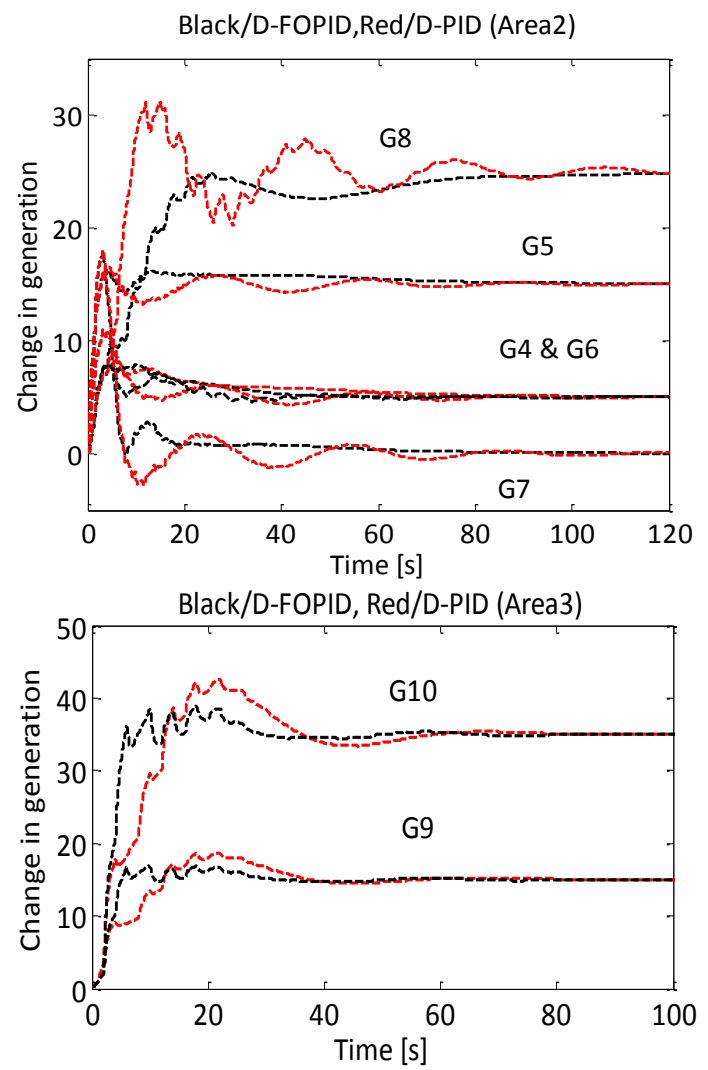

Black/D-FOPID, Red/D-PID (Area4)

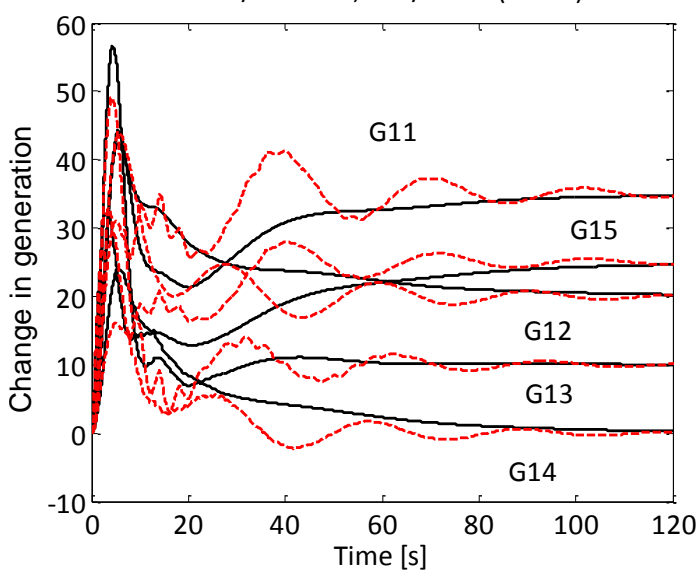

Fig. 13. Gencos's power change in all areas.

The power of $5 \mathrm{MW}$ flow through tie-line (area-2 to area-1) as shown in Fig. 14.

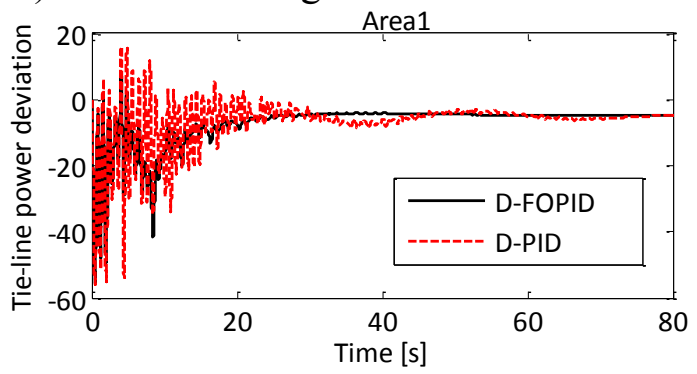

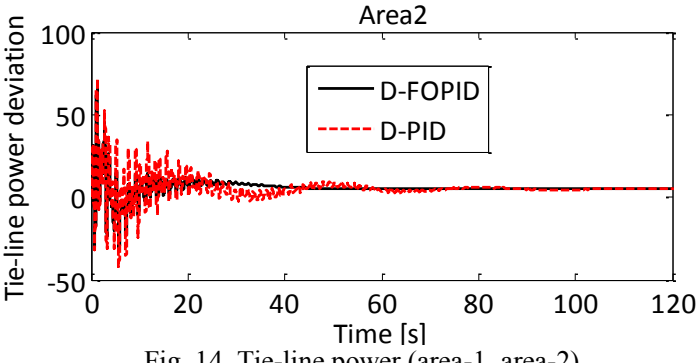

Fig. 14. Tie-line power (area-1, area-2)

Tie-line in area-3 and area-4 settled at zero as shown in Fig. 15.
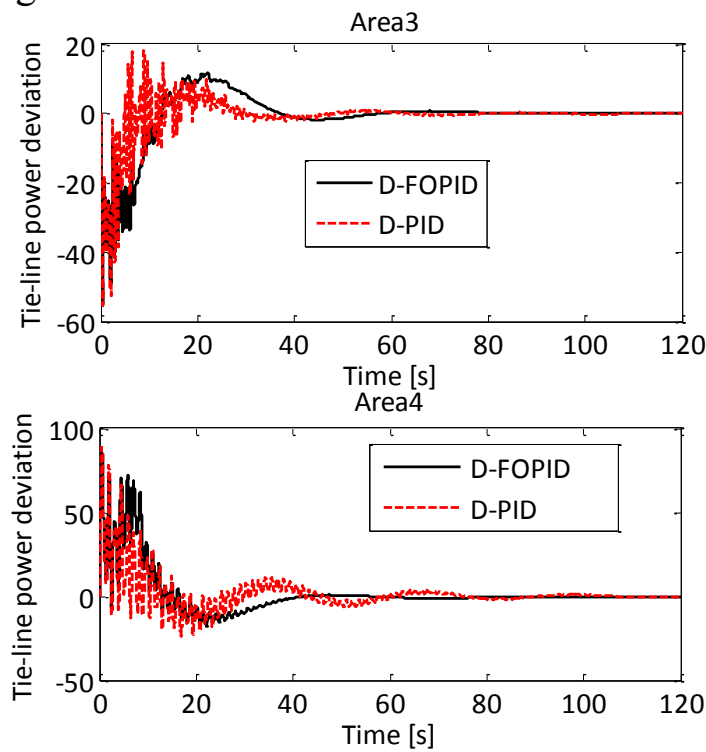

Fig. 15. Tie-line power (area-3, area-4).

After clearing out all the demand, the net change in Gencos/Discos is given in Table 5.

Table 5: Different transaction in different areas.

\begin{tabular}{|c|c|c|c|}
\hline Areas & Bilateral & Poolco & Total \\
\hline Area-1 & $5 \mathrm{MW}$ by G5 & $\begin{array}{l}\mathrm{G} 2=30 \mathrm{MW} \text { (increase) } \\
\mathrm{D} 1=10 \mathrm{MW} \text { (decrease) } \\
\mathrm{G} 1=5 \mathrm{MW} \text { (increase) }\end{array}$ & $50 \mathrm{MW}$ \\
\hline Area-2 & $\begin{array}{l}10 \mathrm{MW} \text { by G11 } \\
5 \mathrm{MW} \text { by G4 }\end{array}$ & $\begin{array}{l}\text { G8 }=25 \mathrm{MW} \text { (increase) } \\
\text { D5 }=5 \mathrm{MW} \text { (decrease) } \\
\text { G4 } 5 \mathrm{MW} \text { (increase) } \\
\mathrm{G} 6=5 \mathrm{MW} \text { (increase) }\end{array}$ & $50 \mathrm{MW}$ \\
\hline Area-3 & none & $\begin{array}{l}\text { G10 }=35 \mathrm{MW} \text { (increase) } \\
\text { G9 }=15 \mathrm{MW} \text { (increase) }\end{array}$ & $50 \mathrm{MW}$ \\
\hline Area-4 & $\begin{array}{c}10 \mathrm{MW} \text { by G5 } \\
20 \mathrm{MW} \text { by G12 }\end{array}$ & $\begin{array}{l}\text { G11 }=25 \mathrm{MW} \text { (increase) } \\
\text { G15 }=25 \mathrm{MW} \text { (increase) } \\
\text { D11 }=10 \mathrm{MW} \text { (decrease) } \\
\text { G12 }=20 \mathrm{MW} \text { (increase) } \\
\text { G13 }=10 \mathrm{MW} \text { (increase) }\end{array}$ & 100MW \\
\hline
\end{tabular}

The settling time comparison is given in Table 6 , which proves the better performance of D-FOPID over D-PID.

Table 6: Settling time comparison of frequency deviations.

\begin{tabular}{ccccc} 
& \multicolumn{2}{c}{ Area-1 } & \multicolumn{2}{c}{ Area-4 } \\
\hline & D-PID & D-FOPID & D-PID & D-FOPID \\
Settling time (sec.) & 100 & 60 & 100 & 60 \\
\hline
\end{tabular}




\section{Compliance with NERC Standard}

In a practical system load varies instantaneously therefore the objective of secondary controller is to keep the frequency deviations within the permissible range. To meet out this, NERC has given two control performance standards, CPS1 \& CPS2 [26]. CPS1 shows relation in frequency deviation and ACE for a given period. Any LFC scheme must have $100 \%$ compliance of CPS 1 .

$$
\text { average_period }\left\lfloor\left(\frac{\mathrm{ACE}_{\mathrm{i}}}{-10 \mathrm{~B}_{\mathrm{i}}}\right) * \Delta \mathrm{F}_{\mathrm{i}}\right\rfloor \leq \varepsilon_{1}^{2},
$$

where $\varepsilon_{1}$ is the constant.

CPS2 shows that average of ACE should be less than $\mathrm{L}_{10}$.

$$
\operatorname{avg}_{10 \text {-minute }}=\left(\mathrm{ACE}_{\mathrm{i}}\right) \leq \mathrm{L}_{10} \text { a }
$$

and

$$
\mathrm{L}_{10}=1.65 \varepsilon_{10} \sqrt{\left(-10 \mathrm{~B}_{\mathrm{i}}\right)}\left(-10 \mathrm{~B}_{\mathrm{s}}\right)
$$

where $\varepsilon_{10}=0.0025 \mathrm{~Hz}, \varepsilon_{1}=0.0131 \mathrm{~Hz}, B_{i}=B_{s}$ $=.0162(\mathrm{MW} / 0.1 \mathrm{~Hz})[31]$. This gives the limit $L_{10}=$ 0.00066825 . For LFC scheme $90 \%$ or more compliance of CPS2 is required.

The compliance of these standards have bene checked for four-area power system. The total time horizon considered is 1 day and there is no unavailable period. The considered load profile is shown in Fig. 16. Fig. 17 shows the load variation curve for area-2. In this work compliance factor (CF) [31] for one hour has been computed.

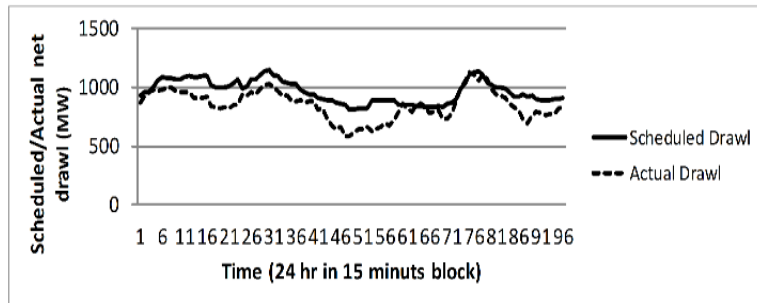

Fig. 16. Scheduled/Actual drawl curve.

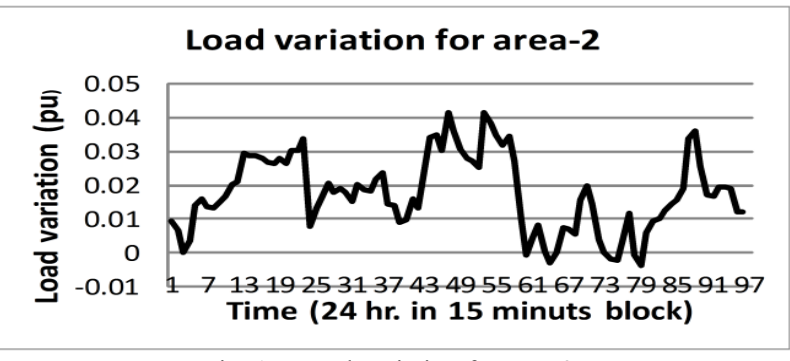

Fig. 17. Load variation for area-2.
The computed $\mathrm{CF}$ value has been used to calculate CPS1 and CPS2. Value of ACE average $\left(\mathrm{ACE}_{\mathrm{av}}\right)$ has been computed for the load variations at 10-minute intervals. Fig. 18 shows the values of $\mathrm{ACE}_{\mathrm{av}}$. On comparing the value of $L_{10}$ with the values of $\mathrm{ACE}_{\mathrm{av}}$ it is observed that there are two violations with D-PID and no violation with the D-FOPID.

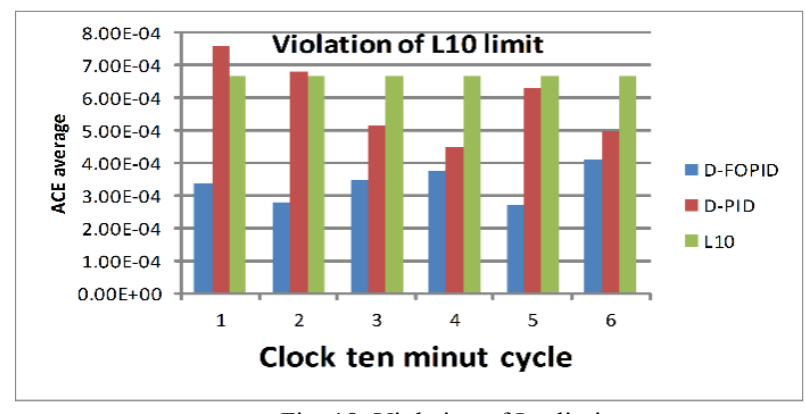

Fig. 18. Violation of $\mathrm{L}_{10}$ limit.

Fig. 19 shows the CPS1 values for D-FOPID and DPID. CPS2 is shown in Fig. 20.

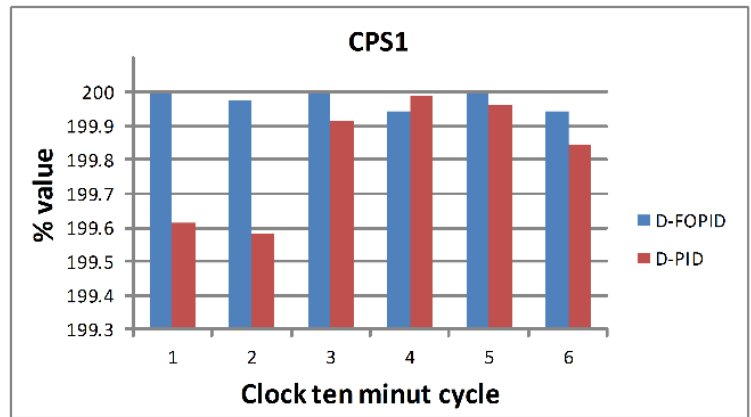

Fig. 19. Comparison of CPS1.

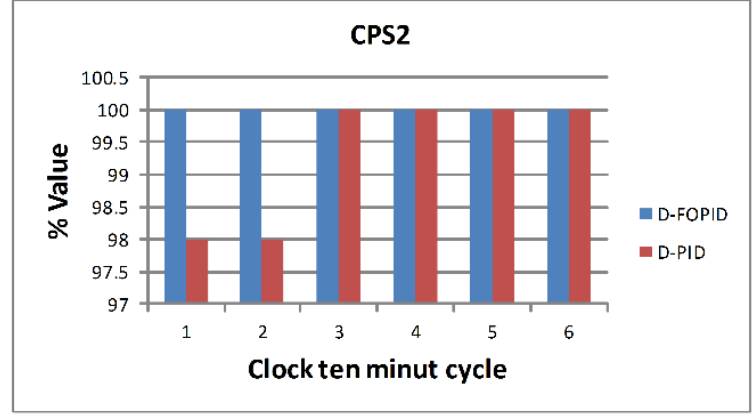

Fig. 20. Comparison of CPS2.

Such results show that the D-FOPID meets the requirement of CPS1 by more than 100 percent and the requirement of CPS2 by 100 percent. It is also seen that relative compliance for D-FOPID based LFC scheme is better than D-PID based LFC scheme. 


\section{Conclusion}

This paper proposed discrete fractional order control scheme for LFC under deregulated environment. An investigation of LFC scheme with transportation delay incorporated in 2-area thermal and 4-area hydro-thermal power system has been carried out. Various power transactions (Poolco, Bilateral) and discrete data of parameters like frequency, tie-line power have been used to design the control schemes. The parameters of D-FOPID/D-PID controllers are determined using BBBC algorithm to effectively regulate the active power outputs of various Gencos. The comparison of performance of D-FOPID/D-PID controller has been carried out and it is seen that oscillations in responses i.e. frequency, tie-power, change in generation have been reduced and settling time improved significantly with D-FOPID controllers. D-FOPID provides wider control range than D-PID. It is also evident that all responses match their theoretical values at steady state. The compliance of the NERC standard has also been established for D-FOPID/DPID controllers, and it observed that relative compliance for D-FOPID based LFC scheme is higher than D-PID based LFC scheme.

\section{References}

[1] Elgerd, I. Olle; and Fosha, C.S.: Optimum megawatt-frequency control of multi area Electric Energy Systems. IEEE Trans. Power Syst. 89, 556563 (1970)

[2] Christie, R.D.; Bose, A.: Load frequency control issues in power system operation after deregulation. IEEE Trans. Power Syst. 11, 1191-1200 (1996)

[3] Singh, V.P.; Kishor, N.; and Samuel, P.: Communication time delay estimation for load frequency control in two-area power system. Ad Hoc Net. 41, 69-85 (2016)

[4] Sonmez, S.; Ayasun, S.; and Emİnoğlu, U.: Computation of time delay margins for stability of a single-area load frequency control system with communication delays. WSEAS Trans. Power Syst., 67-76 (2014)

[5] Zhang, C.; Jiang, L.; and Wu, Q.H.: Delaydependent robust load frequency control for time delay power system. IEEE Trans. Power Syst. 28, 2192-2201 (2013)
[6] Dong, Z., and Zhang, P.: Emerging Techniques in Power System Analysis. I ${ }^{\text {st }}$ ed., Verlag Berlin Heidelberg: Springer, 147-184, (2010)

[7] Martin, K.E.: Synchrophasor standards and guides for the smart grid. In: IEEE Conference on Power Energy Society General Meeting, 1-5 (2013)

[8] Pandey, S.K.; Mohanty, S.R.; Kishor, N.: A literature survey on load-frequency control for conventional and distribution generation power systems. Renew. Sust. Energ. Rev. 25, 318-334 (2013)

[9] Kumar, N.K.; Tyagi, B.; Kumar, V.: Multi-area deregulated automatic generation control scheme of power system using imperialist competitive algorithm based robust controller. IETE J. Resea. T.\&F, 64, 528-537 (2017)

[10] Changmao, Q.; Naiming, Q.; Zhiguo, S.: Fractional PID controller design of hypersonic flight vehicle, computer, mechatronics. In: IEEE 2010 international Conference on Computer, Mechatronics, Control and Electronic Engineering (CMCE). 466-469 (2010)

[11] Hamamci, S.E.: An algorithm for stabilization of fractional-order time delay systems using fractionalorder PID controllers. IEEE Trans. Automat Contr. 52, 1964-9 (2007)

[12] Zamani, M.; Karimi-Ghartemani, M.: Sadati, N.: Parniani, M.: Design of fractional order PID controller for an AVR using particle swarm optimization. Control Eng. Pract. 17, 1380-7 (2009)

[13] Pan, I.; Das, S.: Chaotic multi-objective optimization based design of fractional order $\mathrm{PI}^{\lambda} \mathrm{D}$ $\mu$ controller in AVR system. Int. J. Electr. Power Energy Syst. 43, 393-407 (2012)

[14] Biswas, A.; Das, S.; Abraham, A.; Dasgupta, S.: Design of fractional order PI ${ }^{\lambda} \mathrm{D}^{\mu}$ controllers with an improved differential evolution. Eng. Appl. Artif. Intell. 22, 343-50 (2009)

[15] Padula, F.; Visioli, A.: Tuning rules for optimal PID and fractional order PID controllers. J. Process Contr. 21, 69-81 (2011)

[16] Debbarma, S.; Saikia, L.C.; Sinha, N.: AGC of a multi-area thermal system under deregulated enviornment using a non-integer controller. Electr. Power Syst. Res. 95, 175-183 (2013)

[17] Erol, O.K.; Eskin, I.: New optimization method: big bang-big crunch. Adv. Eng. Softw. 37, 106-111 (2006)

[18] Engin, Y.; Leon, U.: Big Bang- Big Crunch learning method for Fuzzy cognitive maps. Int. J. Comput., 
Elec., Automat., Control and Inf. Eng. 4, 693-702 (2010)

[19] Elgerd, I. Olle.: Electric Energy Systems Theory: An Introduction. New York, McGraw Hill (1983)

[20] Yesil, E.: Interval type-2 fuzzy PID load frequency controller using Big Bang-Big Crunch optimization. Appl. Soft Comput. 15, 100-112 (2014)

[21] Donde, V.; Pai, M.A.; Hiskens, I.A.: Simulation and optimization in an AGC system after deregulation. IEEE Trans. Power Syst. 16, 481-489 (2001)

[22] Tyagi, B.; Srivastava, S.C.: A LQG based load frequency controller in a competitive electricity environment. Int. J. Emerging Electr. Power Syst. 2, $1-13$ (2005)

[23] Kumar, N.K.; Tyagi, B.; Kumar, V.: Multi Area AGC scheme using Imperialist Competition Algorithm in Restructured Power System. Appl. Soft Comput. 48, 160-168 (2016)

[24] Kumar, N.K.; Tyagi, B.; Kumar, V.: Deregulated multiarea AGC scheme using BBBC-FOPID controller. Arab. J. Scien. and Engi. 42, 2641-2649 (2016)

[25] Oustaloup, A.; Mathieu, B.; Lanusse, P.: The Crone control of resonant plants: application to a flexible transmission. Eur. J. Control. 1, 113-121 (1995)

[26] Swati, S.; Yogesh, V.H.: Fractional order PID controller for load frequency control. Energ. Convers. Manage. 85, 343-353 (2014)

[27] Kumar, N.K.; Tyagi, B.; Kumar, V.: Application of Fractional order PID controller for AGC under deregulated environment. Int. J. Autom. and Computing. 15, 84-93 (2017).

[28] Oustaloup, A.; Levron, F.; Mathieu, B.; and Nanot, F.M.: Frequency-band complex noninteger differentiator: Characterization and synthesis. IEEE Trans. Circuits Syst. I Fundam. Theory Appl., 47, 25-39 (2000)
[29] Alaoui, A.: Novel digital integrator and differentiator. Electron. Lett., 29, 376-378 (1993)

[30] Kumar, N.K.; Tyagi, B.; Kumar, V.: Optimization of PID parameters using BBBC for multi-area AGC scheme in deregulated power system. Turk. J. Elec. Engg. and Comput. Scienc. 24, 4105- 4116 (2015)

[31] Sasaki, T.; and Enomoto, K.: Dynamic analysis of generation control performance standards. IEEE Power Eng. Soc. Summer Meet. 17, 806-811 (2002)

\section{Creative Commons Attribution License 4.0 (Attribution 4.0 International, CC BY 4.0)}

This article is published under the terms of the Creative Commons Attribution License 4.0

https://creativecommons.org/licenses/by/4.0/deed.en_US 